\title{
Mechanical properties of a new high entropy alloy with a duplex ultra-fine grained structure
}

\author{
N.D. Stepanov ${ }^{\mathrm{a}, *}$, D.G. Shaysultanov ${ }^{\mathrm{a}}$, R.S. Chernichenko ${ }^{\mathrm{a}}$, D.M. Ikornikov ${ }^{\mathrm{b}}$, V.N. Sanin ${ }^{\mathrm{b}}$, \\ S.V. Zherebtsov ${ }^{\text {a }}$ \\ a Laboratory of Bulk Nanostructured Materials, Belgorod State University, Belgorod 308015, Russia \\ ${ }^{\mathrm{b}}$ Merzhanov Institute of Structural Macrokinetics and Materials Science, Russian Academy of Sciences, Chernogolovka, Moscow 142432, Russia
}

\section{A R T I C L E I N F O}

\section{Keywords:}

High entropy alloys

UFG structure

Phase transformations

Mechanical properties

Grain boundary strengthening

\begin{abstract}
A B S T R A C T
A new approach to increase the tensile performance of high entropy alloys (HEAs) by producing a duplex ultrafine-grained (UFG) structure was reported in this work. A novel HEA based on the CoCrFeNiMn system with substantial amounts of $\mathrm{Al}$ and $\mathrm{C}$ was used for the illustration of this approach. In the as-cast condition the alloy had almost entirely a single face-centered cubic (fcc) phase structure with an insignificant amount of $\mathrm{M}_{23} \mathrm{C}_{6}$ carbides. After cold rolling and annealing at $800-1000{ }^{\circ} \mathrm{C}$ an increased amount of fine second phases, namely $\mathrm{M}_{23} \mathrm{C}_{6}$ carbides and $\mathrm{B} 2$ phase, effectively pinned boundaries of recrystallized fcc grains. As a result, a duplex UFG structure composed of the recrystallized fcc grains and $\mathrm{M}_{23} \mathrm{C}_{6}$ and $\mathrm{B} 2$ particles was produced. The alloy with the UFG structure demonstrated attractive mechanical properties. For example, after annealing at $900{ }^{\circ} \mathrm{C}$ the alloy had the yield strength of $785 \mathrm{MPa}$, the ultimate tensile strength of $985 \mathrm{MPa}$, and elongation to fracture of $32 \%$. The phase composition of the alloy in different conditions was compared with the equilibrium phase diagram obtained using a Thermo-Calc software. Strengthening mechanisms were qualitatively analyzed, and some possibilities for further improvement of strength of the alloy were discussed.
\end{abstract}

\section{Introduction}

Since their introduction in 2004, so-called high entropy alloys (HEAs) - multicomponent alloys of 5 or more principal elements taken in (nearly) equiatomic concentration - have become a highly attractive research field in materials science [1-4]. Although the main researcher's attention was initially focused on alloys with a single solid solution phase structure, it is unclear yet if these concentrated solid solutions principally differ from their dilute counterparts [4-7]. But it is believed that HEAs with more complex, multiphase structures can possess unique properties superior to that of the conventional alloys $[4,8,9]$. For instance, alloys with attractive combinations of room temperature strength and ductility, elevated temperature strength, or high wear resistance have already been demonstrated [10-22].

The most well-studied HEAs family is alloys which are based on 3d transition metals like $\mathrm{Cr}, \mathrm{Mn}, \mathrm{Fe}, \mathrm{Co}$ and $\mathrm{Ni}$ [4]. A typical and quite thoughtfully investigated representative of this family is an equiatomic CoCrFeNiMn alloy (also known as the Cantor alloy) [23-26]. This alloy has a single disordered face-centered cubic (fcc) structure stable at temperatures $>900{ }^{\circ} \mathrm{C}[25,27-32]$ and therefore is widely considered as a "model" single phase HEA. In addition, the CoCrFeNiMn alloy has attractive mechanical properties; namely very high ductility and fracture toughness at room temperature $[24,26]$, which yet increases even more under cryogenic condition. Nevertheless, the strength characteristics of the alloy are quite low $[24,31]$.

Many efforts have been undertaken to improve the strength of the CoCrFeNiMn and similar alloys, and precipitation hardening was found to be a particularly effective approach $[10,33-36]$. Elements like $\mathrm{Al}$ and $\mathrm{Ti}$ are often used to produce strengthening precipitates. For example, proper heat treatment of a single fcc phase $\mathrm{CoCrFeNi}$ alloy containing 4 at $\%$ of $\mathrm{Al}$ and 2 at $\%$ of $\mathrm{Ti}$ resulted in strong precipitation strengthening by $\mathrm{L}_{2}$ phase particles [10]. The alloy demonstrates the ultimate tensile strength of $\sim 1100 \mathrm{MPa}$ with elongation of $\sim 40 \%$ after the optimal processing.

However, there are other options than precipitation hardening. It is well established that the CoCrFeNiMn alloy has a very high Hall-Petch coefficient, about $\sim 0.5 \mathrm{GPa} \times \mu \mathrm{m}^{-.5}[24,37]$. This means that grain refinement can be an effective tool for enhancement strength of the alloy as well. Indeed, a decrease in recrystallized grain size from $144 \mu \mathrm{m}$ to $4.4 \mu \mathrm{m}$ increases the yield strength of the alloy from $\sim 175 \mathrm{MPa}$ to $\sim 375 \mathrm{MPa}$. It might be suggested therefore that grain refinement to, for example, an ultrafine level (grain size $\mathrm{d}<1 \mu \mathrm{m}$ ) can

\footnotetext{
* Correspondence to: Laboratory of Bulk Nanostructured Materials, Belgorod State University, Pobeda 85, Belgorod 308015, Russia.

E-mail address: stepanov@bsu.edu.ru (N.D. Stepanov).
} 
further improve mechanical properties of the alloy.

Some earlier reports demonstrated promising mechanical characteristics of the equiatomic CoCrFeNiMn alloy with the ultrafinegrained (UFG) structure $(\mathrm{d} \approx 0.5 \mu \mathrm{m})[37,38]$. In these works cold working followed by annealing at temperatures $\geq 650^{\circ} \mathrm{C}$ was used to produce the UFG structure. Given relatively fast kinetics of recrystallization and grain growth in the single-phase CoCrFeNiMn alloy $[39,40]$, a very precise control over the annealing condition is needed for preserving the fine grain size. Therefore, the approach used in $[37,38]$ might be rather elusive for practical application. Moreover, annealing of the CoCrFeNiMn alloy at low temperatures can result in the precipitation of second phases like the sigma-phase [27-30] that can drastically deteriorate ductility $[27,41]$.

Another strategy to produce the UFG structure in the CoCrFeNiMn system HEA with sufficient amounts of $\mathrm{Al}$ and $\mathrm{C}$ was used in the present work. The alloy was annealed at $800-1000{ }^{\circ} \mathrm{C}$ following cold rolling. The annealing resulted in the precipitation of $\mathrm{Al}, \mathrm{C}$-rich second phase(s) particles with a high volume fraction due to which fcc grains growth was effectively inhibited. As a result, a duplex UFG structure was produced. Mechanical properties of the alloy with the duplex UFG structure were studied.

\section{Materials and methods}

In this work, the program alloy was fabricated via the self-propagating high-temperature synthesis (SHS)-casting technique. The use of highly exothermic thermite-type SHS mixtures makes it possible to achieve temperatures high enough (above $2500^{\circ} \mathrm{C}$ ) to obtain molten combustion products and, as a result, cast products (ingots). Previous studies have demonstrated that the SHS process under high gravity conditions is optimal for the chemical homogeneity of the produced ingot and easy removal of the slag $\left(\mathrm{Al}_{2} \mathrm{O}_{3}\right)[42,43]$. The high gravity SHS-casting has been already successfully used to produce different $3 \mathrm{~d}$ transition metals HEAs [43-45]. The synthesis of the program alloy was carried out in a centrifugal SHS setup [46] under artificial gravity of 50-60 G. The initial products were taken in the form of a mixture of powders including oxides of the target elements, $\mathrm{Al}$ (both as the metal reducer and alloying element), and pure C (graphite powder). The size and purity of the powders used are specified in Table 1 . Prior to the synthesis, the powders were mechanically mixed for $20 \mathrm{~min}$. The mixture was placed in a graphite mold of $80 \mathrm{~mm}$ diameter. The inner surface of the graphite mold was covered with $\mathrm{Al}$ oxide $\left(\mathrm{Al}_{2} \mathrm{O}_{3}\right)$ to ensure the minimal interaction between the mold and the melt.

The obtained ingot was measured $40 \mathrm{~mm}$ diameter $\times 7 \mathrm{~mm}$ height. The result of the chemical analysis (the concentrations of the metallic elements were measured by energy dispersive spectrometry (EDX) over area $\approx 1 \times 1 \mathrm{~mm}^{2}$, the concentration of carbon was measured using a LECO analyzer) of the obtained ingot is given in Table 2. Samples for microstructural characterization and further thermomechanical processing were cut from the as-cast ingot by an electric discharge machine. The samples for the thermomechanical processing were measured $4 \times 5 \times 22 \mathrm{~mm}^{3}$. These samples were cold rolled to the final thickness of $\approx 0.32 \mathrm{~mm}$ (a thickness reduction of $92 \%$ ) with a reduction per pass of $5-10 \%$. Some of the cold-rolled samples were annealed

Table 1

Ingredients used for the SHS-casting procedure.

\begin{tabular}{lll}
\hline Ingredients & The particle size d, $\mu \mathrm{m}$ & Purity, \% \\
\hline $\mathrm{NiO}$ & $<40$ & 99.0 \\
$\mathrm{Cr}_{2} \mathrm{O}_{3}$ & $<20$ & 99.2 \\
$\mathrm{Co}_{3} \mathrm{O}_{4}$ & $<10$ & 99.6 \\
$\mathrm{Fe}_{2} \mathrm{O}_{3}$ & $<50$ & 99.3 \\
$\mathrm{MnO}_{2}$ & $<30$ & 99.7 \\
$\mathrm{Al}$ & $<140$ & 98.0 \\
$\mathrm{C}$ & $<50$ & 99.8 \\
\hline
\end{tabular}

Table 2

Chemical composition of the studied alloy (in at\%).

\begin{tabular}{lllllll}
\hline Co & Cr & Fe & Ni & Mn & Al & C \\
\hline 21.55 & 18.73 & 21.44 & 21.44 & 10.01 & 5.31 & 1.52 \\
\hline
\end{tabular}

at $800{ }^{\circ} \mathrm{C}, 900{ }^{\circ} \mathrm{C}$, or $1000^{\circ} \mathrm{C}$ for $30 \mathrm{~min}$. For the annealing, the samples were placed in a preheated oven and held for the desired amount of time; cooling was carried on laboratory air.

Structures of the alloy in different conditions (as-cast, cold-rolled to $92 \%$ reduction, annealed at $800-1000^{\circ} \mathrm{C}$ ) were studied by scanning (SEM) and transmission (TEM) electron microscopy. The samples for scanning electron microscopy were prepared by careful mechanical polishing. All microstructural observations of the cold-rolled and annealed specimens were performed at the mid-thickness rolling plane. The SEM studies were performed using an FEI Quanta 600 FEG microscope equipped with an EDX detector. The samples for the TEM observations were produced by mechanical thinning of discs (measured $3 \mathrm{~mm}$ diameter $\times \sim 100 \mu \mathrm{m}$ thickness) followed by twin-jet electropolishing in a mixture of $95 \% \mathrm{C}_{2} \mathrm{H}_{5} \mathrm{OH}$ and $5 \% \mathrm{HClO}_{4}$ at the $27 \mathrm{~V}$ potential. The TEM investigations were performed using a JEOL JEM2100 microscope with an accelerating voltage of $200 \mathrm{kV}$ equipped with an EDX detector. The grain size was measured using SEM/TEM images per standard linear interception method. At least 300 grains per each condition were analyzed. The fraction of the second phase(s) was measured from SEM-BSE images using a Digimizer Image Analysis software and a binarization procedure and from TEM bright-field images using a grid point counting method.

Microhardness measurements and tensile tests were performed to estimate mechanical properties of the alloy in different conditions. The microhardness was measured at room temperature using $300 \mathrm{~g}$ load. At least 10 measurements for each data point were made. Tensile flat dogbone specimens with the gauge measured $6 \times 3 \times 0.3 \mathrm{~mm}^{3}$ were cut by the electric discharge machine. The long axis of the specimens was aligned with the rolling direction. These specimens were further pulled at a constant crosshead speed of $0.36 \mathrm{~mm} / \mathrm{min}$ in an Instron 5882 test machine to fracture. Elongation to fracture was determined by measurements of the spacing between marks designating the gauge length before and after the test. Three samples for each condition were tested.

\section{Results}

Fig. 1 illustrates the initial (as-cast) structure of the alloy. The XRD pattern shows the presence of the major fcc phase $(\mathrm{a}=3.596 \mathrm{~nm})$ and some peaks from presumably $\mathrm{M}_{23} \mathrm{C}_{6}$ carbides (Fig. 1a). The SEM-BSE image demonstrates a relatively coarse-grained (the average grain size $\mathrm{d} \approx 80 \mu \mathrm{m}$ ) predominantly single-phase structure (Fig. 1b). However, some fine, elongated second phase particles were detected at the grain boundaries (a higher magnification is inserted in Fig. 1b). Also, some pores can be observed as dark, irregularly shaped objects in Fig. 1a (some of them are shown with arrows). The TEM investigations (Fig. 1c) have confirmed that the second phase particles were $\mathrm{M}_{23} \mathrm{C}_{6}$ type carbides, while the matrix had a disordered fcc structure. The carbides measured $180 \pm 120 \mathrm{~nm}$ length $\times 45 \pm 25 \mathrm{~nm}$ width can be found both at grain boundaries and inside fcc grains. The volume fraction of the carbides was $\sim 0.03$. The TEM-based EDX has revealed that the particles were primarily composed of $\mathrm{Cr}(\sim 64$ at $\%$ (out of metallic elements; C concentration was not measured by TEM-EDX)). The microhardness of the as-cast alloy was $167 \mathrm{HV}$.

Cold rolling to a high thickness reduction had resulted in significant microstructure refinement (Fig. 2). A typical heavily deformed microstructure with high dislocation density was observed; the microstructure mostly composed of subgrains with irregular shape and blurry wide boundaries (Fig. 2a). Occasionally twinned areas can be found (some of them are identified with arrows in Fig. 2b). The suppression of 


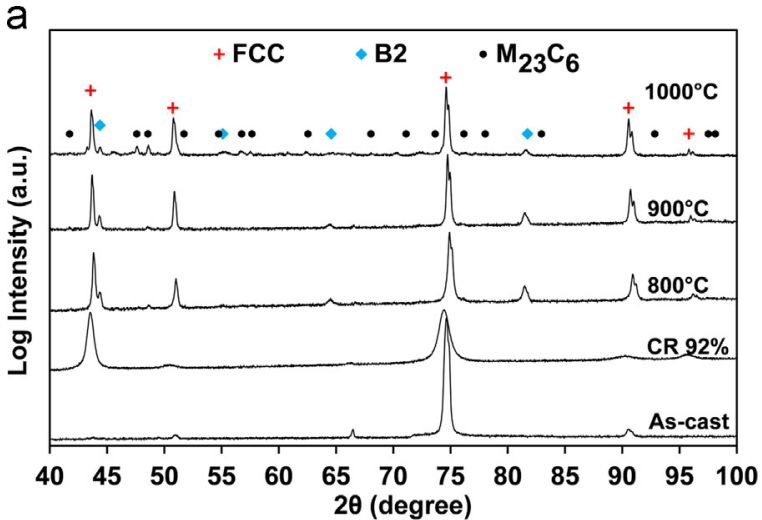

b

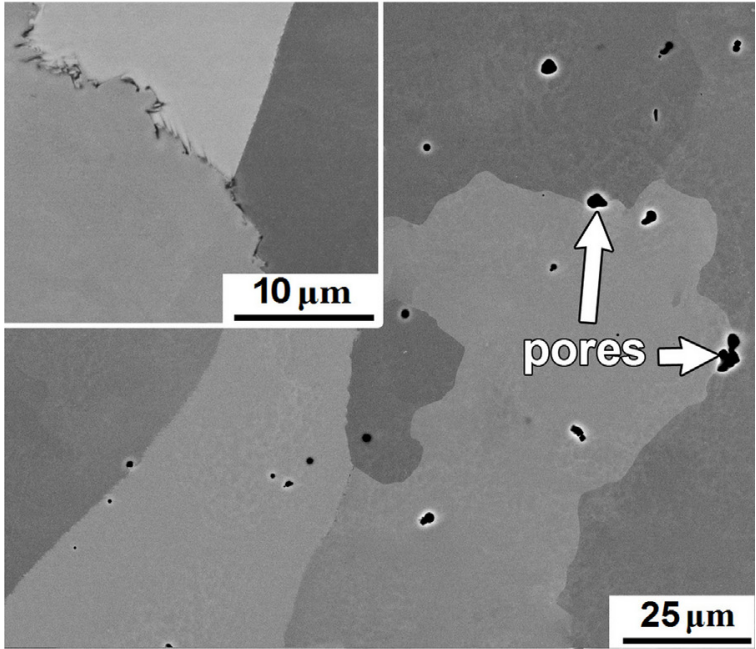

C

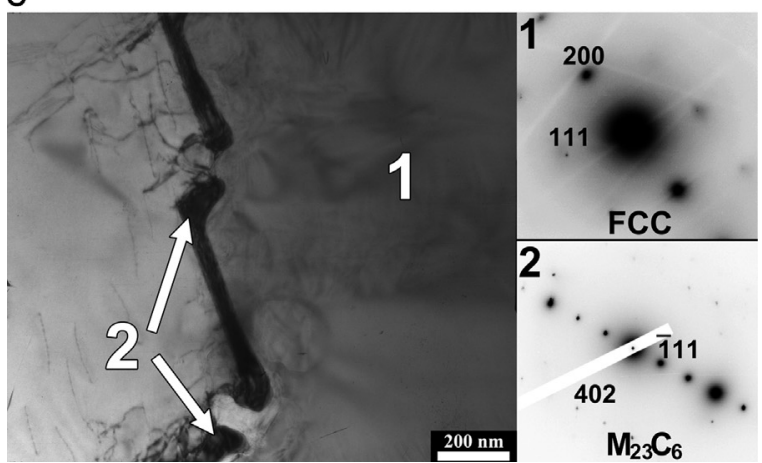

Fig. 1. Structure of the program alloy in the as-cast condition: (a) - XRD pattern, (b) - SEM-BSE image, (c) - TEM bright-field image with corresponding selected area electron diffraction patters (SAEDs). Note that the XRD patterns for other conditions are also presented in Fig. 1a.

twinning can be attributed to the presence of $\mathrm{Al}$ and $\mathrm{C}$ in agreement with some recent data $[22,44]$. The carbide particles (not shown) were not affected by deformation. No changes in phase composition were detected by the XRD analysis (Fig. 1a). Cold rolling resulted also in an increase in the microhardness of the alloy to $478 \mathrm{HV}$, i.e. $\sim 3$ times higher than that of the as-cast condition.

Annealing of the rolled alloy at temperatures $800-1000{ }^{\circ} \mathrm{C}$ resulted in partial (at $800^{\circ} \mathrm{C}$, Fig. 3a) or complete (at $900{ }^{\circ} \mathrm{C}$ and $1000^{\circ} \mathrm{C}$, Fig. $3 \mathrm{~b}$ and d) recrystallization of the fcc matrix phase. After annealing at $800{ }^{\circ} \mathrm{C}$ the recrystallized fraction and the size of the recrystallized grains (according to the SEM data) were 0.85 and $0.55 \pm 0.22 \mu \mathrm{m}$,
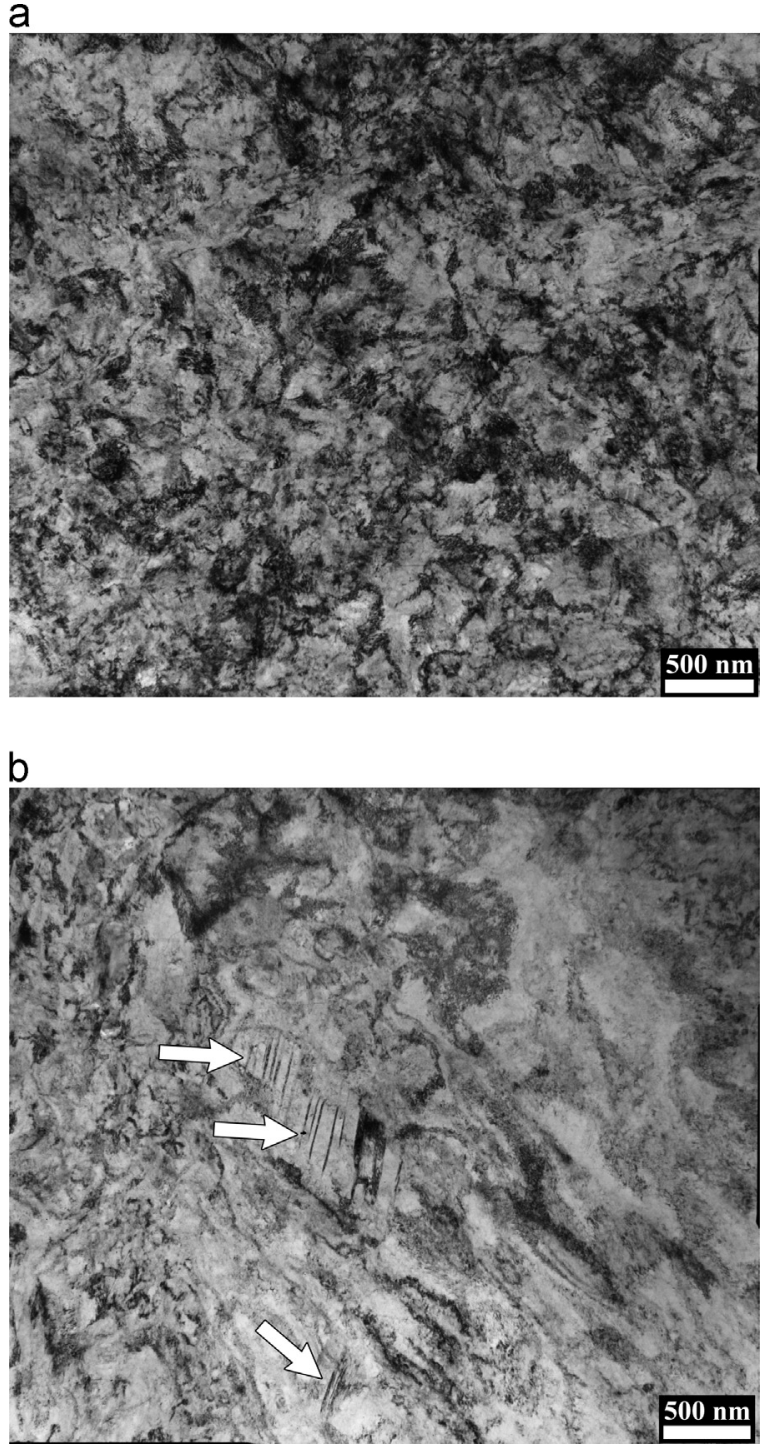

Fig. 2. Microstructure of the program alloy after cold rolling to $92 \%$ thickness reduction; TEM bright-field images. Deformation twins are indicated with arrows in Fig. 2 b.

respectively, (Table 3). An increase in the annealing temperature to $900{ }^{\circ} \mathrm{C}$ or $1000{ }^{\circ} \mathrm{C}$ resulted in an increase in grain size to $1.03 \pm 0.35 \mu \mathrm{m}$ or $1.75 \pm 0.85 \mu \mathrm{m}$, respectively. Recrystallized grains contained numerous annealing twins.

Besides recrystallization of the fcc phase, annealing resulted in the precipitation of a significant amount of second phase(s) particles (seen as small equiaxed dark areas in Fig. 3). The estimated fraction of the second phase(s) decreased from 0.199 after annealing at $800{ }^{\circ} \mathrm{C}$ to 0.142 after annealing at $1000^{\circ} \mathrm{C}$ (Table 3). On the other hand, the average size of the second phase(s) particles increased from $0.24 \pm 0.10 \mu \mathrm{m}$ to $0.56 \pm 0.27 \mu \mathrm{m}$ when temperature increased from $800^{\circ} \mathrm{C}$ to $1000^{\circ} \mathrm{C}$. In the partially recrystallized condition (annealing at $800^{\circ} \mathrm{C}$ ) the second phase(s) were predominantly found in the recrystallized regions (Fig. 3c). The particles located at the grain boundaries were generally coarser than the particles inside recrystallized grains (see the high magnification insert in Fig. 3b).

It worth noting that the size of the recrystallized grains depended on the presence of the second phase particles at grain boundaries. Due to some heterogeneity in the second phase particles distribution after annealing at 900 or $1000{ }^{\circ} \mathrm{C}$, the grain size also had an obvious difference. For example the microstructure at the top of Fig. $3 \mathrm{~b}$ is evidently 


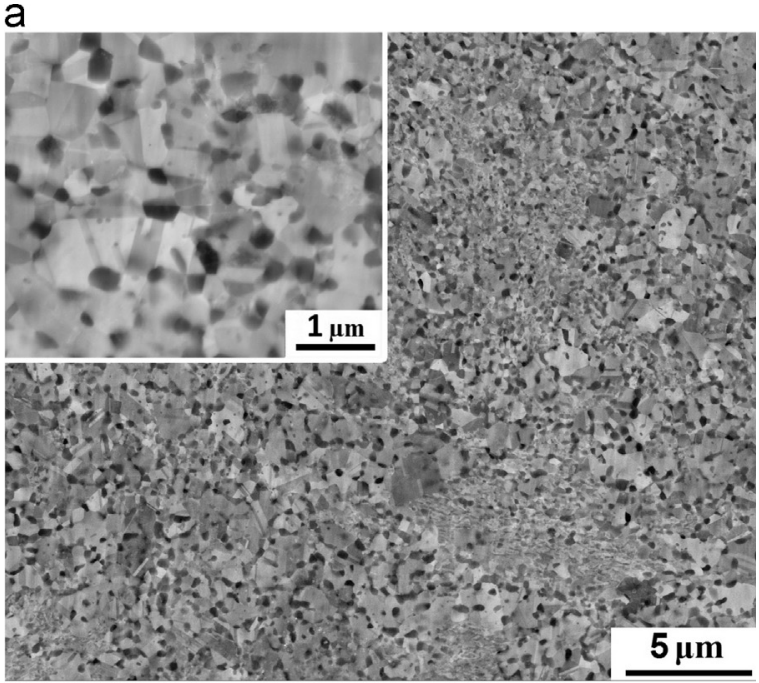

b

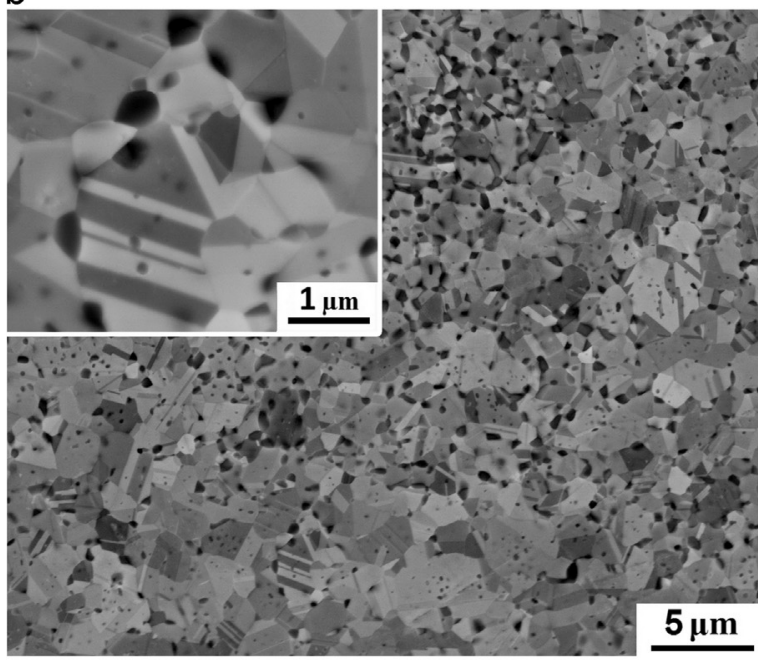

C

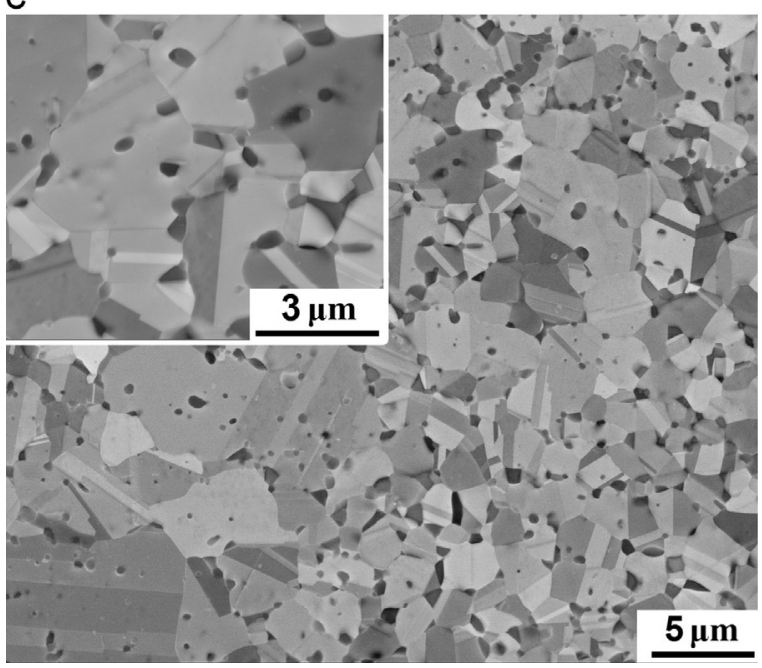

Fig. 3. SEM-BSE images of the studied alloy after cold rolling to $92 \%$ thickness reduction and subsequent annealing for $30 \mathrm{~min}$ at (a) $-800{ }^{\circ} \mathrm{C}$, (b) $-900{ }^{\circ} \mathrm{C}$, (c) $-1000^{\circ} \mathrm{C}$. finer than that in the bottom that can be associated with a non-uniform distribution of the second phase particles in different parts of the microstructure. A similar situation can be observed after annealing at $1000^{\circ} \mathrm{C}$ (compare the grain size and the second phase particles fraction in the left lower and right lower corners of Fig. 3c).

To gain insight into the structure of the alloy after annealing, TEM studies were performed (Fig. 4). TEM has confirmed the response of the fcc matrix to the annealing observed earlier via SEM (Fig. 3, Table 3): incomplete recrystallization at $800{ }^{\circ} \mathrm{C}$ (Fig. 4a) and complete recrystallization and continuous growth of the recrystallized grains at higher temperatures (Fig. 4b and c and Table 3). In the unrecrystallized areas obvious signs of the recovery development was observed (compare Fig. 4a and Fig. 2). Note that the size of the recrystallized grains determined using either SEM or TEM was within the error margin. However, the average size of the second phase(s) determined by TEM was noticeably lower, and the fraction of the second phase(s) was higher than the corresponding values obtained by SEM (Table 3). Most probably, this discrepancy can be attributed to the presence of very fine particles with the size of several tens nanometers (Fig. 4) which cannot be readily distinguished by SEM.

The second phase(s) particles can be found inside grains or at boundaries of fcc grains, including triple junctions (Fig. 4). Also, after high-temperature annealing some relatively coarse particles can be identified as individual "grains" as they have boundaries with several adjacent fcc grains (point \#3 in Fig. 4c). Selected area electron diffraction patterns (SAEDs) were used to identify the crystal structure of the second phases. It was found that after annealing in the interval $800-1000^{\circ} \mathrm{C}$, the alloy was composed of the fcc matrix (labeled as \#1 in Fig. 4), $\mathrm{M}_{23} \mathrm{C}_{6}$ type carbides (labeled as \#2) and B2 phase (labeled as \#3). The same fcc, $\mathrm{M}_{23} \mathrm{C}_{6}$ carbides, and $\mathrm{B} 2$ phases were detected by XRD (Fig. 1a). In general, the B2 particles were coarser, tended to have a polygonal shape, and were often found at grain boundaries of the fcc phase, while the carbides were usually finer, rounded, and located inside fcc grains. Nevertheless, the accurate distinguishing between the B2 phase and the carbide particles based on their morphology was not possible. Therefore, the size and the fraction of the second phases were measured jointly (i.e. the fraction of second phase(s) in Table 3 represents both carbide and $\mathrm{B} 2$ phases fraction).

The chemical compositions of the structural constituents (i.e. the fcc, B2, and $\mathrm{M}_{23} \mathrm{C}_{6}$ carbide phases) determined by TEM-EDX, are shown in Table 4. The concentration of carbon was not analyzed as the energy resolution of the EDX system does not allow a correct analysis of the light elements. The measured composition of the fcc phase has retained rather close to the nominal one (Table 1 ), however it was depleted of $\mathrm{Al}$ and enriched in $\mathrm{Co}$ and $\mathrm{Fe}(\sim 24-26$ at $\%$ each). The carbides were primarily composed of $\mathrm{Cr}(\approx 63$ at $\%)$, and depleted of other metallic elements. The B2 phase, in turn, was enriched with $\mathrm{Ni}(\sim 35-37$ at $\%)$, $\mathrm{Mn}(\sim 14-17$ at $\%)$, and $\mathrm{Al}(\sim 14-21$ at $\%)$, and depleted of the rest of the elements. The chemical composition of the carbides did not change after annealing at the studied temperatures. In turn, the fcc matrix and the B2 phase particles changed their composition depending on the annealing temperature; the partitioning of elements increased with decreasing the temperature. For example, the concentration of $\mathrm{Al}$ in the fcc phase decreased from 3.4 to 1.7 at $\%$ with a decrease in annealing temperature from 1000 to $800{ }^{\circ} \mathrm{C}$; at the same time in the $\mathrm{B} 2$ phase the percentage of $\mathrm{Al}$ increased from 14.5 to $21.2 \mathrm{at} \%$.

Tensile tests were used to evaluate mechanical properties of the alloy after cold rolling and subsequent annealing. The engineering stress-strain curves are shown in Fig. 5, and the resulting tensile properties are summarized in Table 5. After cold rolling with a high thickness reduction (92\%) the alloy demonstrated very high strength (the ultimate tensile strength was $1545 \mathrm{MPa}$ ) and simultaneously very limited strain hardening capacity resulting in very low ductility; the total elongation was only $4 \%$. The high strength of the cold-worked alloy can be attributed to dislocation and grain (twin) boundary strengthening in accordance with previous results $[47,48]$. The strength 
Table 3

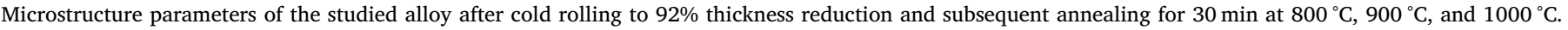

\begin{tabular}{|c|c|c|c|c|c|c|}
\hline \multirow[t]{2}{*}{ Annealing temperature } & \multicolumn{2}{|c|}{ fcc grain size, $\mu \mathrm{m}$} & \multicolumn{2}{|c|}{ Second phase(s) particle size, $\mu \mathrm{m}$} & \multicolumn{2}{|c|}{ Volume fraction of second phase(s), \% } \\
\hline & SEM & TEM & SEM & TEM & SEM & TEM \\
\hline $800^{\circ} \mathrm{C}$ & $0.55 \pm 0.22$ & $0.66 \pm 0.19$ & $0.24 \pm 0.10$ & $0.10 \pm 0.05$ & 19.9 & 22.8 \\
\hline $900{ }^{\circ} \mathrm{C}$ & $1.03 \pm 0.35$ & $0.92 \pm 0.42$ & $0.37 \pm 0.18$ & $0.20 \pm 0.11$ & 17.3 & 18.7 \\
\hline $1000{ }^{\circ} \mathrm{C}$ & $1.75 \pm 0.85$ & $1.48 \pm 0.39$ & $0.56 \pm 0.27$ & $0.32 \pm 0.15$ & 14.1 & 16.9 \\
\hline
\end{tabular}
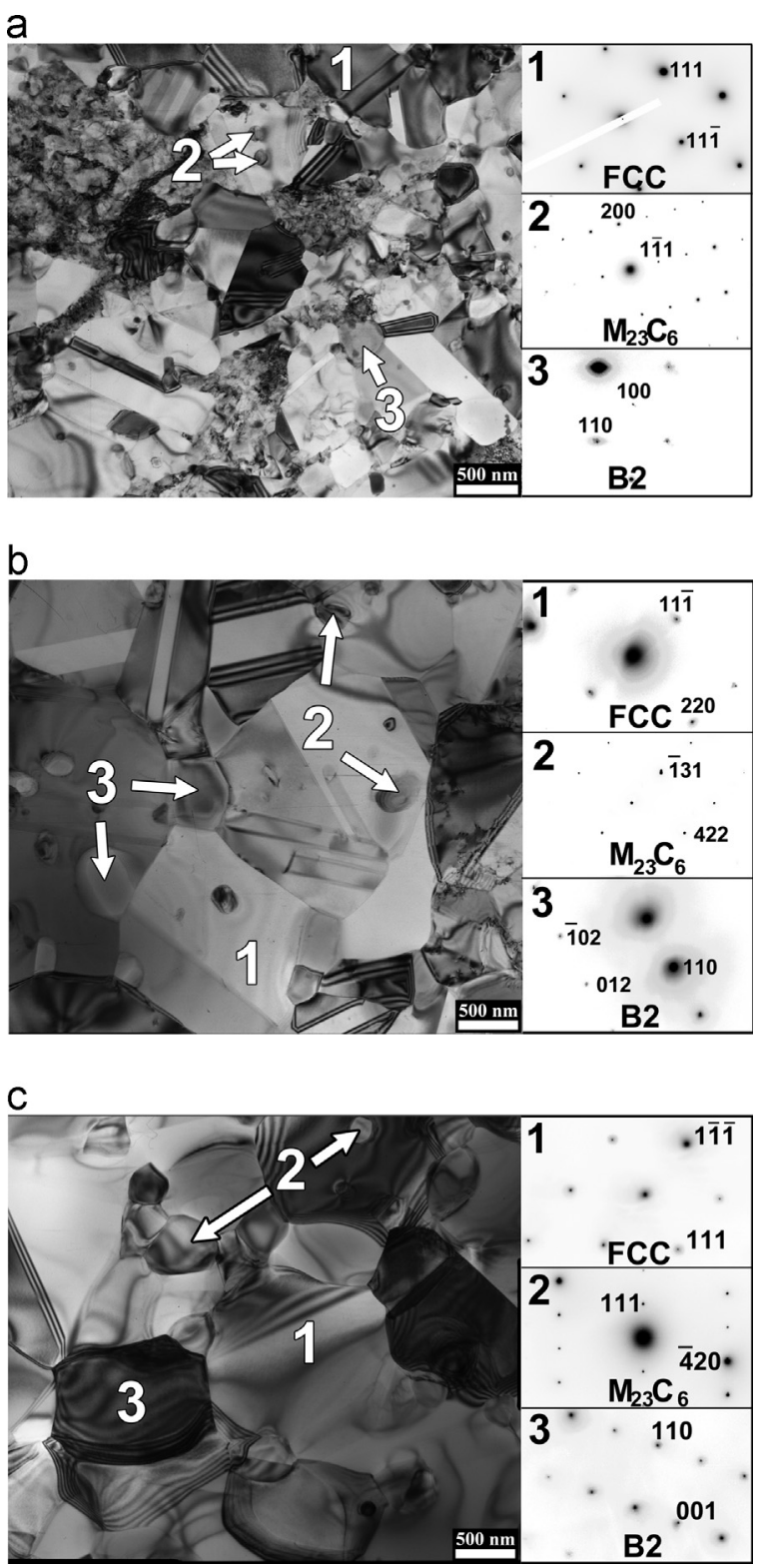

Fig. 4. TEM bright-field images of the program alloy after cold rolling to $92 \%$ thickness reduction and subsequent annealing for $30 \mathrm{~min}$ at (a) $-800^{\circ} \mathrm{C}$, (b) $-900^{\circ} \mathrm{C}$, (c) $-1000^{\circ} \mathrm{C}$. SAEDs taken from the constitutive phases indicated with number are also shown. The chemical composition of the structural constituents indicated with numbers is given in Table 4 .

of the alloy gradually decreased and ductility increased with an increase in the annealing temperature. For instance, the yield strength decreased from $850 \mathrm{MPa}$ to $530 \mathrm{MPa}$ and elongation to fracture rose from $20 \%$ to $35 \%$ when the annealing temperature increased from $800^{\circ} \mathrm{C}$ to $1000^{\circ} \mathrm{C}$. Note that the annealed alloy had high ductility despite still rather limited strain hardening capacity (Fig. 5). For example
Table 4

Chemical compositions of the structural constituents of the program alloy after cold rolling to $92 \%$ thickness reduction and subsequent annealing at $800-1000^{\circ} \mathrm{C}$ for $30 \mathrm{~min}$.

\begin{tabular}{llllllll}
\hline Structural constituent & $\mathrm{Co}$ & $\mathrm{Cr}$ & $\mathrm{Fe}$ & $\mathrm{Ni}$ & $\mathrm{Mn}$ & $\mathrm{Al}$ \\
\hline$\#$ & Designation & $800{ }^{\circ} \mathrm{C}$ & & & & & \\
1 & $\mathrm{fcc}$ & 25.2 & 18.4 & 26 & 18.4 & 10.3 & 1.7 \\
2 & $\mathrm{M}_{23} \mathrm{C}_{6}$ & 9.2 & 63.6 & 10.7 & 8.8 & 6.4 & 1.3 \\
3 & $\mathrm{~B} 2$ & 11.8 & 5.1 & 8.1 & 37.1 & 16.7 & 21.2 \\
& & $900{ }^{\circ} \mathrm{C}$ & & & & & \\
1 & $\mathrm{fcc}$ & 24.9 & 17.7 & 25.1 & 18.8 & 10.8 & 2.7 \\
2 & $\mathrm{M}_{23} \mathrm{C}_{6}$ & 10 & 63.4 & 11.5 & 7.9 & 6.5 & 0.7 \\
3 & $\mathrm{~B} 2$ & 13.7 & 6.4 & 8.8 & 36.0 & 15.9 & 19.2 \\
& & $1000{ }^{\circ} \mathrm{C}$ & & & & & \\
1 & $\mathrm{fcc}$ & 24.3 & 17.8 & 24.2 & 19.3 & 11 & 3.4 \\
2 & $\mathrm{M}_{23} \mathrm{C}_{6}$ & 9.3 & 63.2 & 11.5 & 8.2 & 6.9 & 0.9 \\
3 & $\mathrm{~B} 2$ & 16.6 & 8.2 & 11.9 & 34.8 & 14.0 & 14.5 \\
\hline
\end{tabular}

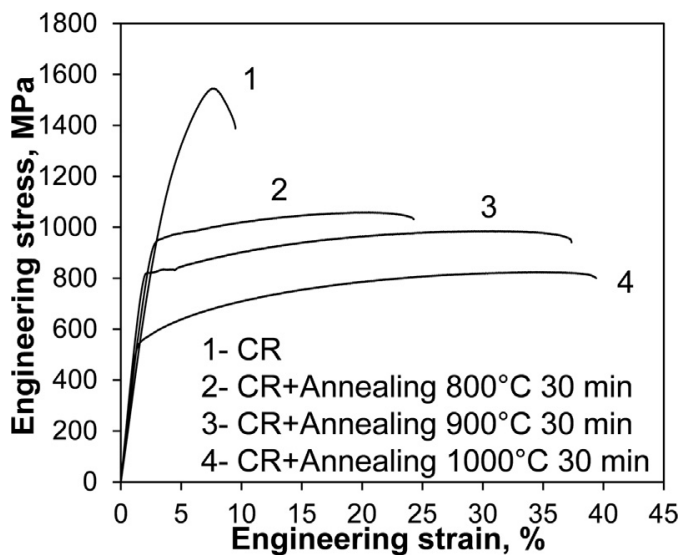

Fig. 5. Engineering tensile stress-strain curves of the program alloy in different conditions: cold rolled to $92 \%(\mathrm{CR})$ and cold rolled and then annealed at $800{ }^{\circ} \mathrm{C}$, $900{ }^{\circ} \mathrm{C}$, or $1000^{\circ} \mathrm{C}$.

Table 5

Tensile mechanical properties of the program alloy in different conditions: cold rolled to $92 \%$ (CR) and cold rolled and then annealed at $800{ }^{\circ} \mathrm{C}, 900{ }^{\circ} \mathrm{C}$, or $1000^{\circ} \mathrm{C}$.

\begin{tabular}{lllll}
\hline Condition & YS, MPa & UTS, MPa & UE, \% & EF, \% \\
\hline $\mathrm{CR}$ & 960 & 1545 & 2.5 & 4 \\
$\mathrm{CR}+$ annealing $800^{\circ} \mathrm{C}$ & 850 & 1060 & 16 & 20 \\
$\mathrm{CR}+$ annealing $900^{\circ} \mathrm{C}$ & 785 & 985 & 26 & 32 \\
$\mathrm{CR}+$ annealing $1000^{\circ} \mathrm{C}$ & 530 & 825 & 30 & 35 \\
\hline
\end{tabular}

after annealing at $900{ }^{\circ} \mathrm{C}$ the uniform elongation was $26 \%$, although the difference between the yield strength and the ultimate tensile strength was only $200 \mathrm{MPa}$ (785 MPa and $985 \mathrm{MPa}$, respectively). The presence of a plateau straight after the yield point of the specimen annealed at $900{ }^{\circ} \mathrm{C}$ should also be mentioned. In general, the alloy after annealing demonstrated quite balanced mechanical properties: the ultimate tensile strength of $825-1060 \mathrm{MPa}$ and the total elongation of $20-35 \%$. 


\section{Discussion}

The obtained results demonstrated that cold rolling and subsequent annealing of the initially predominantly single fcc phase high entropy alloy containing a large amount of $\mathrm{Al}$ and $\mathrm{C}$ resulted in: (i) the precipitation of a large fraction of the second phases, namely, the $\mathrm{M}_{23} \mathrm{C}_{6}$ type carbides and the $\mathrm{B} 2$ phase and (ii) recrystallization of the fcc phase, thereby promoting the formation of a specific, duplex-type equiaxed structure with the size of both the fcc grains and second phases particles falling into the UFG region. Moreover, the alloy with the UFG duplex structure exhibited an attractive combination of mechanical properties. Although the formation of a fine-grained duplex structure in HEAs has already been reported [49-51], in these earlier studies the initial materials were dual-phase. The current investigation was focused on an almost single-phase alloy with the fraction of the second phases $\sim 0.03$ in the initial condition (Fig. 1). The phase transformations, recrystallization behavior, and strengthening mechanisms of the alloy are analyzed in details below.

Conventionally, phase diagrams are utilized for understanding of phase transformations in the alloys. Although the phase diagrams are usually available for binary and ternary systems, CALPHAD approach implemented in several commercial software packages can be used to produce phase diagrams for more complex systems. In the present work a Thermo-Calc software with a TCHEA2 database developed especially for high entropy alloys was used to calculate the equilibrium phase diagram for the program alloy. The obtained phase diagram is shown in Fig. 6.

The investigated alloy started to solidify at $1340^{\circ} \mathrm{C}$ through a single fcc phase. The solidification terminated at $1285^{\circ} \mathrm{C}$; the as-solidified structure was composed of the primary fcc phase with a small amount of $\mathrm{M}_{7} \mathrm{C}_{3}$ carbides $(\sim 1.8 \%)$ which appeared at the last stages of the solidification. The $\mathrm{M}_{7} \mathrm{C}_{3}$ carbides were almost stoichiometric $\mathrm{Cr}_{7} \mathrm{C}_{3}$ carbides with a minor presence of some other elements. During further decrease in temperature, the fraction of the carbides slowly increased reaching 0.036 at $1100{ }^{\circ} \mathrm{C}$. At almost the same temperature $\left(1098{ }^{\circ} \mathrm{C}\right)$, the precipitation of an $\mathrm{Al}$, Ni-rich $\mathrm{B} 2$ phase occurred. The fraction of this phase grew steadily reaching $\approx 0.2$ at $800{ }^{\circ} \mathrm{C}$. Also, the transformation of the $\mathrm{M}_{7} \mathrm{C}_{3}$ carbides to $\mathrm{M}_{23} \mathrm{C}_{6}$ occurred at temperatures of $\sim 800-850^{\circ} \mathrm{C}$; yet they were still composed almost exclusively of $\mathrm{Cr}$ and C. The fraction of the $\mathrm{M}_{23} \mathrm{C}_{6}$ carbides reached $\approx 0.07$ at $800^{\circ} \mathrm{C}$. Note that the amount of $\mathrm{C}$ in the fcc phase was very low ( $\leq 0.3 \mathrm{at} \%)$ and did not change pronouncedly at $\mathrm{T}<1100{ }^{\circ} \mathrm{C}$, while the $\mathrm{Al}$ concentration gradually decreased starting from the solvus temperature of the B2 phase $\left(\sim 1100^{\circ} \mathrm{C}\right)$.

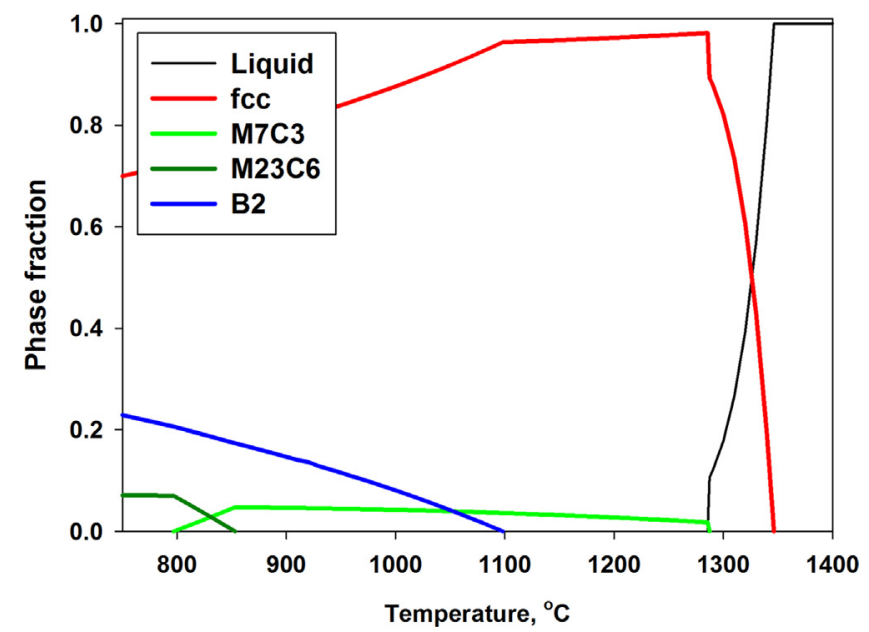

Fig. 6. Equilibrium phase diagram of the program alloy produced by the Thermo-Calc software. The chemical composition of the alloy was taken from Table 2 .
The experimental phase composition reasonably agreed with the Thermo-Calc predictions although there was an apparent difference. The as-cast alloy was composed of the fcc matrix with a small fraction (0.03) of the $\mathrm{M}_{23} \mathrm{C}_{6}$ carbides (Fig. 1c), while the phase diagram (Fig. 6) suggested the fcc $+M_{7} C_{3}$ structure. Since no signs of $M_{7} C_{3}$ carbides were found after annealing at $800-1000{ }^{\circ} \mathrm{C}$ (Fig. 1a), therefore only the $\mathrm{M}_{23} \mathrm{C}_{6}$ type carbides are suggested to be stable in the present alloy, like that in a similar alloy with lower $\mathrm{Al}$ and C content [45]. This contradiction can be associated with a more complex chemical composition of the carbides (Table 3) in comparison with the almost stoichiometric binary $\mathrm{Cr}_{7 / 23} \mathrm{C}_{3 / 6}$ carbides predicted by the Thermo-Calc.

The precipitation of a large fraction of the $\mathrm{B} 2$ and carbide particles after annealing at $800{ }^{\circ} \mathrm{C}, 900^{\circ} \mathrm{C}$ or $1000^{\circ} \mathrm{C}$ (Figs. 3 and 4, Table 3) was in excellent agreement with the equilibrium phase diagram (Fig. 6). Moreover, the observed amount of the second phases correlated well with the thermodynamic predictions; for instance the experimental fraction after annealing at $800^{\circ} \mathrm{C}$ was $\sim 0.20-0.23$ (Table 3), while the calculated one was $\sim 0.27$. Some decrease in the fraction of the second phases with an increase in the annealing temperature (Table 3) also agreed with the equilibrium predictions. These observations suggested that the phase composition of the alloy after the short-term annealing was rather close to the equilibrium one(s) possibly due to high density of defects (dislocations, subgrain boundaries, and twin boundaries) in the cold-rolled material which most likely (i) accelerated diffusion and (ii) served as the preferred nucleation sites. The equilibrium phase diagram (Fig. 6) suggested also that after annealing (i) the fraction of the B2 particles was considerably greater than that of carbides; (ii) the observed changes in the fraction of the phases with annealing temperature were primarily associated with the $\mathrm{B} 2$ phase. Although the separate evaluation of the volume fractions of the $\mathrm{M}_{23} \mathrm{C}_{6}$ and $\mathrm{B} 2$ phase particles was not performed (Table 3), the chemical analysis of the constitutive phases (Table 4) showed rather strong changes in the composition of both the fcc and B2 phases with annealing temperature (the content of $\mathrm{Al}$ was particularly susceptible), while the composition of the $\mathrm{M}_{23} \mathrm{C}_{6}$ carbides had barely changed.

Microstructure analysis of the alloy after annealing at $800-1000{ }^{\circ} \mathrm{C}$ (Figs. 3 and 4) suggested that the $\mathrm{B} 2$ and $\mathrm{M}_{23} \mathrm{C}_{6}$ particles precipitation is closely interrelated with recrystallization of the fcc phase. On the one hand, due to the fast grain-boundary diffusion the particles nucleated at (sub)grains grew more intensively in comparison with the particles nucleated within grains (see, for example, the insert in Fig. 3b). On the other hand, a high amount of the second phases pinned grain boundaries thereby restricting their migration [52]. In the areas with a lower fraction of the second phase particles the recrystallized grain size is noticeably larger than that in the present of pinning particles (Fig. 3b). Although the obtained data is insufficient to quantify the effect of the second phases on the recrystallization processes in the fcc phase, this influence can be estimated by the comparison of the recrystallized fcc grain size obtained in the current study with the grain sizes reported for the equiatomic CoCrFeNiMn alloy after annealing under similar conditions (80-90\% cold rolling followed by an hour annealing at $800-1000^{\circ} \mathrm{C}$ ) [24,30,39,53] (Fig. 7). TEM data (Table 3) was used for the investigated alloy.

Fig. 7 clearly shows that the fcc grain size in the program duplex alloy was considerably lower than that in a nearly single fcc phase CoCrFeNiMn alloy [30]. The difference was at least $\sim 3-4$ times (with the data of [53] at $800{ }^{\circ} \mathrm{C}$ and $900{ }^{\circ} \mathrm{C}$ ), reaching in some cases an order of magnitude. Partially, this difference can be attributed to different processing conditions; for instance lower annealing time in the current study (30 min vs $1 \mathrm{~h}$ in $[24,30,39,53])$. However, longer annealing itself cannot be responsible for such an increase in the grains size. For example, an increase in annealing time from 0.5 to $1 \mathrm{~h}$ resulted in some increase in the grain size from 5.2 to $6.9 \mu \mathrm{m}$ in the CoCrFeNiMn alloy, i.e. the grain size increased only by $\sim 1.5$ times. Therefore, it seems reasonable to suggest that the duplex structure of the alloy is mainly responsible for the grain size preserving. But the present work cannot 


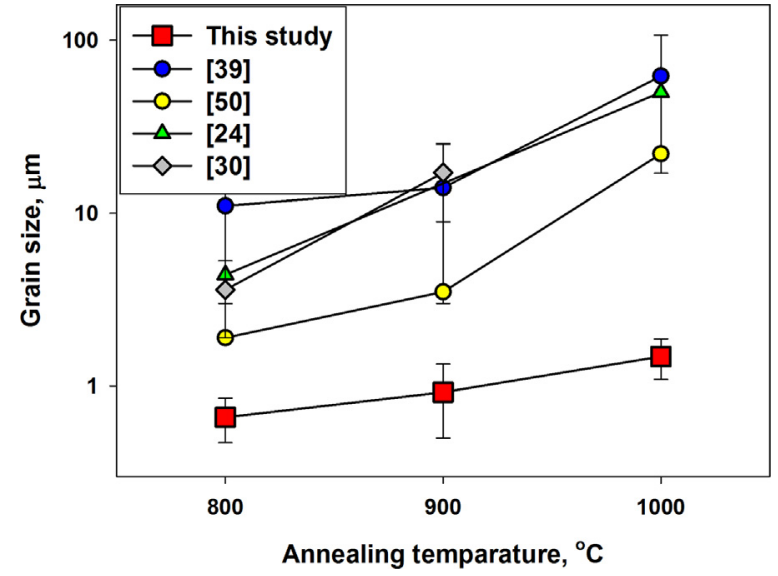

Fig. 7. Semilog dependence of grain size in the program alloy and in the equiatomic CoCrFeNiMn alloy on annealing temperature.

give an exact information on what fraction and sizes of the second phase(s) particles provide more efficient pinning effect; this question requires additional studies.

The specific UFG duplex structure of the alloy should be responsible for encouraging mechanical properties, namely, high strength of the alloy (Fig. 5, Table 5). Apparently, the strength of the alloy should benefit from both a fine size of the fcc grains and the presence of a large fraction of the hard $\mathrm{B} 2$ and $\mathrm{M}_{23} \mathrm{C}_{6}$ particles. Besides, after annealing at $800^{\circ} \mathrm{C}$ a significant fraction of unrecrystallized material with high dislocation density and fine grain (twin) boundary spacing remained (Figs. 3a and 4a). To estimate the contribution of all potential strengthening factors, a rule of mixture was used [54]:

$Y S=\left(1-V_{S P}-V_{\text {Unrec }}\right) * Y S_{f c c}+V_{\text {Unrec }} * Y S_{\text {Unrec }}+V_{S P} * Y S_{S P}$

where $Y S$ - is the yield strength of the alloy; $V_{S P}$ - is the volume fraction of the second phases; $V_{\text {Unrec }}$ - is the unrecrystallized volume fraction; $Y S_{f c c}$ - is the yield strength of the recrystallized fcc phase; $Y S$ Unrec - is the yield strength of the unrecrystallized material and $Y S S_{S P}$ denotes the yield strength of the second phases. In turn, the yield strength of the recrystallized fcc phase depending on the grain size can be expressed as:

$Y S_{f c c}=\sigma_{0}+K_{H P} * d$

where $\sigma_{O}$ is the friction stress, $K_{H P}$ is the Hall-Petch coefficient, and $d$ is the recrystallized fcc grain size. The values of $\sigma_{O}$ and $K_{H P}$ were taken from [24] for the "pure" CoCrFeNiMn alloy $\left(\sigma_{O}=125 \mathrm{MPa} ; K_{H P}\right.$ $\left.=494 \mathrm{MPa}^{*} \mu \mathrm{m}^{-0.5}\right)$. Since there is no reliable data on the yield strength of the unrecrystallized areas as soon as the second phases in the annealed alloy, therefore, the following assumptions were made: (i) the yield strength of the cold-rolled alloy (Table 5) was used as the yield strength of the unrecrystallized areas, i.e. the effect of recovery on strength of the unrecrystallized areas was neglected; (ii) the yield strength of the alloy with somewhat similar composition and almost a single B2 phase structure $\left(\mathrm{Al}_{28} \mathrm{Co}_{20} \mathrm{Cr}_{11} \mathrm{Fe}_{15} \mathrm{Ni}_{26}, 1253 \mathrm{MPa}\right.$, [55]) was used as $Y S_{S P}$. The values of $d$ and $V_{S P}$ were taken from Table 2 (TEM data), the $V_{\text {Unrec }}$ value was 0.15 at $800^{\circ} \mathrm{C}$ and 0 at $900{ }^{\circ} \mathrm{C}$ and $1000^{\circ} \mathrm{C}$. The results of the calculations using Eqs. (1) and (2) are shown in Fig. 8.

The comparison of the experimental data (Table 5) and the values of the yield strength calculated using Eqs. (1)-(2) shows good agreement (Fig. 8). The analysis of the contributions of the different structural constituents suggests that strength of the alloy is mostly due to the ultrafine-grained fcc phase (in accordance with Eq. (2)). Meanwhile the second phase particles provide both direct strengthening (Fig. 8) and indirect strengthening by pinning fcc grain boundaries [56], while the unrecrystallized areas do not produce any noticeable strengthening due to their low fraction. However, the higher is the yield strength the lower

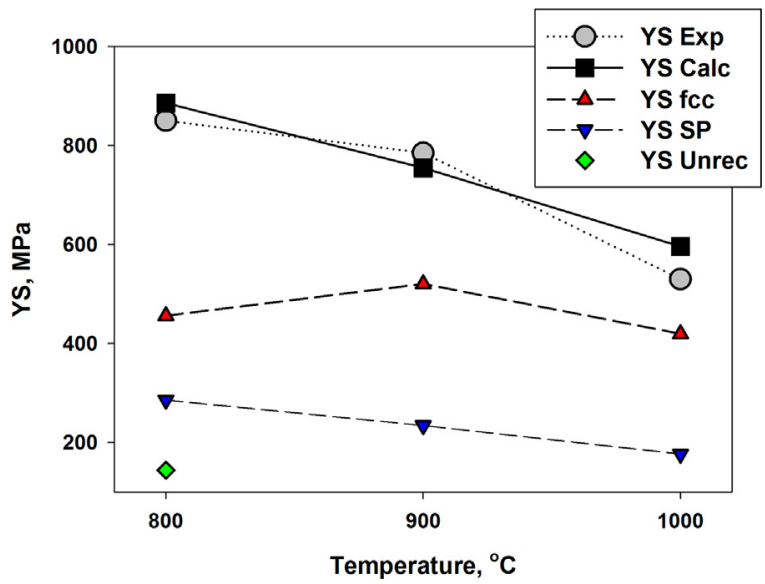

Fig. 8. Contributions of different structural constituents to the yield strength of the program alloy as a function of annealing temperature.

is the ductility of the alloy, most probably, due to lower work hardening capacity (Table 5). Yet in all conditions the alloy demonstrated rather weak work hardening capacity $(\Delta$ (UTS-YS) $\approx 200-300 \mathrm{MPa}$ (Table 5)). Most probably this is due to suppression of twinning in the presence of $\mathrm{Al}$ and $\mathrm{C}$ (see the cold-rolled structure, Fig. 2). Fine grains after annealing can make the alloy even less prone to twinning $[38,57,58]$.

To sum up, the present study has demonstrated a relatively simple method to produce a duplex UFG structure in the $3 \mathrm{~d}$ transition element based HEA that resulted in an attractive combination of strength and ductility. In general, the possibility to transform a coarse-grained single phase microstructure of the alloy into a fine-grained duplex one allows varying mechanical behavior of the alloy in a wide range which is promising for potential applications. Based on the current results and data of some other works, it might be suggested that properties of the duplex UFG HEAs can be further increased not only by tailoring the fcc grain size and the fraction of the second phase(s), but also by adjusting solid solution strengthening $[59,60]$, control over the deformation mechanisms [61,62], and (probably) precipitation strengthening [35]. However, further studies are required to establish composition-structure-properties relationships in duplex UFG HEAs in more details and to determine the alloys and processing conditions resulting in the best combination of strength and ductility.

\section{Conclusions}

In the present work, microstructure and mechanical properties of the high entropy alloy composed of $\mathrm{Co}, \mathrm{Cr}, \mathrm{Fe}, \mathrm{Ni}$ (18.7-22.5 at $\%$ each), $\mathrm{Mn}(10.0 \%), \mathrm{Al}(5.3 \%)$, and C (1.5\%) in the as-cast condition and after cold rolling (92\% thickness reduction) with subsequent annealing at 800-1000 ${ }^{\circ} \mathrm{C}$ were studied. Following conclusions were drawn:

1) The as-cast alloy was composed of coarse fcc grains with a small fraction of the $\mathrm{M}_{23} \mathrm{C}_{6}$ carbides. Cold rolling resulted in the substructure development and strong refinement of the fcc matrix. In addition, the microhardness of the alloy increased from $167 \mathrm{HV}$ in the as-cast condition to $478 \mathrm{HV}$ after cold rolling.

2) Annealing of the cold-rolled alloy resulted in the precipitation of the $\mathrm{B} 2$ and $\mathrm{M}_{23} \mathrm{C}_{6}$ particles. The $\mathrm{B} 2$ phase was enriched with $\mathrm{Ni}$ and $\mathrm{Al}$, while the carbides were primarily composed of $\mathrm{Cr}$. The aggregate fraction of the second phases decreased from $22.8 \%$ to $16.9 \%$ and the size of the particles increased from $0.10 \mu \mathrm{m}$ to $0.32 \mu \mathrm{m}$ when the annealing temperature increased from $800{ }^{\circ} \mathrm{C}$ to $1000{ }^{\circ} \mathrm{C}$. The precipitation of the $\mathrm{B} 2$ and $\mathrm{M}_{23} \mathrm{C}_{6}$ phases after annealing was found to be in agreement with the equilibrium phase diagram for the alloy constructed using the Thermo-Calc software.

3) Annealing also resulted in recrystallization of the heavily-deformed 
fcc phase - partial at $800{ }^{\circ} \mathrm{C}$ and complete at $900{ }^{\circ} \mathrm{C}$ and $1000^{\circ} \mathrm{C}$. The recrystallized grain size increased from $0.55 \mu \mathrm{m}$ to $1.75 \mu \mathrm{m}$ with an increase in the annealing temperature from $800^{\circ} \mathrm{C}$ to $1000^{\circ} \mathrm{C}$. The small size of the fcc grains was attributed to the pinning effect of the second phase particles. The combination of the fine fcc grains and the large fraction of the second phase particles resulted in the formation of a duplex UFG structure in the alloy after annealing.

4) The cold-rolled alloy had high strength (the ultimate tensile strength was $1545 \mathrm{MPa}$ ) but low ductility (the elongation to fracture was only 4\%). Annealing resulted in a gradual increase of ductility with an increase in temperature together with some decrease in strength. Yet a combination of high strength and ductility can be achieved after annealing. For example, after annealing at $800^{\circ} \mathrm{C}$ the alloy had the yield strength of $785 \mathrm{MPa}$, the ultimate tensile strength of $985 \mathrm{MPa}$, and the elongation to fracture of $32 \%$. The high strength of the alloy with the duplex UFG structure was primarily attributed to the small fcc grain size.

\section{Acknowledgments}

The authors gratefully acknowledge the financial support from the Russian Science Foundation Grant No. 14-19-01104. The authors are grateful to the personnel of the Joint Research Center, "Technology and Materials", Belgorod State University, for their assistance with the instrumental analysis.

\section{References}

1] J.-W. Yeh, S.-K. Chen, S.-J. Lin, J.-Y. Gan, T.-S. Chin, T.-T. Shun, C.-H. Tsau, S.Y. Chang, Nanostructured high-entropy alloys with multiple principal elements: novel alloy design concepts and outcomes, Adv. Eng. Mater. 6 (2004) 299-303, http://dx.doi.org/10.1002/adem.200300567.

[2] Y. Zhang, T.T. Zuo, Z. Tang, M.C. Gao, K.A. Dahmen, P.K. Liaw, Z.P. Lu, Microstructures and properties of high-entropy alloys, Prog. Mater. Sci. 61 (2014), http://dx.doi.org/10.1016/j.pmatsci.2013.10.001.

[3] E.J. Pickering, N.G. Jones, High-entropy alloys: a critical assessment of their founding principles and future prospects, Int. Mater. Rev. (2016) 183-202, http:// dx.doi.org/10.1080/09506608.2016.1180020.

[4] D.B. Miracle, O.N. Senkov, A critical review of high entropy alloys and related concepts, Acta Mater. 122 (2017) 448-511, http://dx.doi.org/10.1016/j.actamat. 2016.08.081.

[5] L.R. Owen, E.J. Pickering, H.Y. Playford, H.J. Stone, M.G. Tucker, N.G. Jones, An assessment of the lattice strain in the $\mathrm{CrMnFeCoNi}$ high-entropy alloy, Acta Mater. 122 (2017) 11-18, http://dx.doi.org/10.1016/j.actamat.2016.09.032.

[6] M. Laurent-Brocq, L. Perrière, R. Pirès, Y. Champion, From high entropy alloys to diluted multi-component alloys: range of existence of a solid-solution, Mater. Des. 103 (2016) 84-89, http://dx.doi.org/10.1016/j.matdes.2016.04.046.

[7] M. Laurent-Brocq, L. Perrière, R. Pirès, F. Prima, P. Vermaut, Y. Champion, From diluted solid solutions to high entropy alloys: on the evolution of properties with composition of multi-components alloys, Mater. Sci. Eng. A 696 (2017) 228-235, http://dx.doi.org/10.1016/j.msea.2017.04.079.

[8] O.N. Senkov, J.D. Miller, D.B. Miracle, C. Woodward, Accelerated exploration of multi-principal element alloys with solid solution phases, Nat. Commun. 6 (2015) 6529, http://dx.doi.org/10.1038/ncomms7529.

[9] D. Miracle, J. Miller, O. Senkov, C. Woodward, M. Uchic, J. Tiley, Exploration and development of high entropy alloys for structural applications, Entropy 16 (2014) 494-525, http://dx.doi.org/10.3390/e16010494.

[10] J.Y. He, H. Wang, H.L. Huang, X.D. Xu, M.W. Chen, Y. Wu, X.J. Liu, T.G. Nieh, K. An, Z.P. Lu, A precipitation-hardened high-entropy alloy with outstanding tensile properties, Acta Mater. 102 (2016) 187-196, http://dx.doi.org/10.1016/j.actamat. 2015.08.076.

[11] Z. Li, K.G. Pradeep, Y. Deng, D. Raabe, C.C. Tasan, Metastable high-entropy dualphase alloys overcome the strength-ductility trade-off, Nature 534 (2016), http:// dx.doi.org/10.1038/nature17981.

[12] Z. Li, C.C. Tasan, H. Springer, B. Gault, D. Raabe, Interstitial atoms enable joint twinning and transformation induced plasticity in strong and ductile high-entropy alloys, Sci. Rep. 7 (2017) 40704, http://dx.doi.org/10.1038/srep40704.

[13] O.N. Senkov, S.V. Senkova, C. Woodward, D.B. Miracle, Low-density, refractory multi-principal element alloys of the $\mathrm{Cr}-\mathrm{Nb}-\mathrm{Ti}-\mathrm{V}-\mathrm{Zr}$ system: microstructure and phase analysis, Acta Mater. 61 (2013) 1545-1557, http://dx.doi.org/10.1016/j. actamat.2012.11.032.

[14] O.N. Senkov, S.V. Senkova, D.B. Miracle, C. Woodward, Mechanical properties of low-density, refractory multi-principal element alloys of the $\mathrm{Cr}-\mathrm{Nb}-\mathrm{Ti}-\mathrm{V}-\mathrm{Zr}$ system, Mater. Sci. Eng. A 565 (2013) 51-62, http://dx.doi.org/10.1016/j.msea. 2012.12.018.

[15] O.N. Senkov, C. Woodward, D.B. Miracle, Microstructure and properties of aluminum-containing refractory high-entropy alloys, JOM 66 (2014) 2030-2042, http://dx.doi.org/10.1007/s11837-014-1066-0.

[16] O.N. Senkov, S.V. Senkova, C.F. Woodward, Effect of aluminum on the microstructure and properties of two refractory high-entropy alloys, Acta Mater. 68 (2014) 214-228, http://dx.doi.org/10.1016/j.actamat.2014.01.029.

[17] O.N. Senkov, J.K. Jensen, A.L. Pilchak, D.B. Miracle, H.L. Fraser, Compositional variation effects on the microstructure and properties of a refractory high-entropy superalloy AlMo 0.5 NbTa 0.5 TiZr, Mater. Des. (2017), http://dx.doi.org/10.1016/ j.matdes.2017.11.033.

[18] N.D. Stepanov, N.Y. Yurchenko, D.V. Skibin, M.A. Tikhonovsky, G.A. Salishchev, Structure and mechanical properties of the AlCrxNbTiV ( $\mathrm{x}=0,0.5,1,1.5)$ high entropy alloys, J. Alloy. Compd. 652 (2015) 266-280, http://dx.doi.org/10.1016/j. jallcom.2015.08.224.

[19] N.Y. Yurchenko, N.D. Stepanov, S.V. Zherebtsov, M.A. Tikhonovsky, G.A. Salishchev, Structure and mechanical properties of B2 ordered refractory AlNbTiVZrx (x = 0-1.5) high-entropy alloys, Mater. Sci. Eng. A 704 (2017) 82-90, http://dx.doi.org/10.1016/j.msea.2017.08.019.

[20] N.Y. Yurchenko, N.D. Stepanov, D.G. Shaysultanov, M.A. Tikhonovsky, G.A. Salishchev, Effect of $\mathrm{Al}$ content on structure and mechanical properties of the AlxCrNbTiVZr (x = 0;0.25; 0.5; 1) high-entropy alloys, Mater. Charact. 121 (2016) 125-134, http://dx.doi.org/10.1016/j.matchar.2016.09.039.

[21] M.-H. Chuang, M.-H. Tsai, W.-R. Wang, S.-J. Lin, J.-W. Yeh, Microstructure and wear behavior of AlxCo1.5CrFeNi1.5Tiy high-entropy alloys, Acta Mater. 59 (2011) 6308-6317, http://dx.doi.org/10.1016/j.actamat.2011.06.041.

[22] N.D. Stepanov, D.G. Shaysultanov, R.S. Chernichenko, N.Y. Yurchenko, S.V. Zherebtsov, M.A. Tikhonovsky, G.A. Salishchev, Effect of thermomechanical processing on microstructure and mechanical properties of the carbon-containing CoCrFeNiMn high entropy alloy, J. Alloy. Compd. 693 (2017) 394-405, http://dx. doi.org/10.1016/j.jallcom.2016.09.208.

[23] B. Cantor, I.T.H. Chang, P. Knight, A.J.B. Vincent, Microstructural development in equiatomic multicomponent alloys, Mater. Sci. Eng. A 375 (2004) 213-218, http:// dx.doi.org/10.1016/j.msea.2003.10.257.

[24] F. Otto, A. Dlouhý, C. Somsen, H. Bei, G. Eggeler, E.P. George, The influences of temperature and microstructure on the tensile properties of a CoCrFeMnNi highentropy alloy, Acta Mater. 61 (2013), http://dx.doi.org/10.1016/j.actamat.2013. 06.018 .

[25] F. Otto, Y. Yang, H. Bei, E.P.P. George, Relative effects of enthalpy and entropy on the phase stability of equiatomic high-entropy alloys, Acta Mater. 61 (2013) 2628-2638, http://dx.doi.org/10.1016/j.actamat.2013.01.042.

[26] B. Gludovatz, A. Hohenwarter, D. Catoor, E.H. Chang, E.P. George, R.O. Ritchie, A fracture-resistant high-entropy alloy for cryogenic applications, Science (80-) 345 (2014), http://dx.doi.org/10.1126/science.1254581.

[27] B. Schuh, F. Mendez-Martin, B. Völker, E.P.P. George, H. Clemens, R. Pippan, A. Hohenwarter, B. Völker, E.P.P. George, H. Clemens, R. Pippan, A. Hohenwarter, Mechanical properties, microstructure and thermal stability of a nanocrystalline CoCrFeMnNi high-entropy alloy after severe plastic deformation, Acta Mater. 96 (2015) 258-268, http://dx.doi.org/10.1016/j.actamat.2015.06.025.

[28] F. Otto, A. Dlouhý, K.G. Pradeep, M. Kuběnová, D. Raabe, G. Eggeler, E.P. George, Decomposition of the single-phase high-entropy alloy $\mathrm{CrMnFeCoNi}$ after prolonged anneals at intermediate temperatures, Acta Mater. 112 (2016), http://dx.doi.org/ 10.1016/j.actamat.2016.04.005.

[29] E.J. Pickering, R. Muñoz-Moreno, H.J. Stone, N.G. Jones, Precipitation in the equiatomic high-entropy alloy CrMnFeCoNi, Scr. Mater. 113 (2016), http://dx.doi. org $/ 10.1016 / j$.scriptamat.2015.10.025.

[30] N.D. Stepanov, D.G. Shaysultanov, M.S. Ozerov, S.V. Zherebtsov, G.A. Salishchev, Second phase formation in the CoCrFeNiMn high entropy alloy after recrystallization annealing, Mater. Lett. 185 (2016) 1-4, http://dx.doi.org/10.1016/j.matlet. 2016.08.088.

[31] G.A. Salishchev, M.A. Tikhonovsky, D.G. Shaysultanov, N.D. Stepanov, A.V. Kuznetsov, I.V. Kolodiy, A.S. Tortika, O.N. Senkov, Effect of Mn and v on structure and mechanical properties of high-entropy alloys based on CoCrFeNi system, J. Alloy. Compd. 591 (2014) 11-21, http://dx.doi.org/10.1016/j.jallcom. 2013.12.210.

[32] M. Laurent-Brocq, A. Akhatova, L. Perrière, S. Chebini, X. Sauvage, E. Leroy, Y. Champion, Insights into the phase diagram of the CrMnFeCoNi high entropy alloy, Acta Mater. 88 (2015), http://dx.doi.org/10.1016/j.actamat.2015.01.068.

[33] J.Y. He, H. Wang, Y. Wu, X.J. Liu, H.H. Mao, T.G. Nieh, Z.P. Lu, Precipitation behavior and its effects on tensile properties of FeCoNiCr high-entropy alloys, Intermetallics 79 (2016) 41-52, http://dx.doi.org/10.1016/j.intermet.2016.09. 005.

[34] B. Gwalani, V. Soni, M. Lee, S. Mantri, Y. Ren, R. Banerjee, Optimizing the coupled effects of Hall-Petch and precipitation strengthening in a Al0.3CoCrFeNi high entropy alloy, Mater. Des. 121 (2017) 254-260, http://dx.doi.org/10.1016/j.matdes. 2017.02.072.

[35] W.H. Liu, T. Yang, C.T. Liu, Precipitation hardening in CoCrFeNi-based high entropy alloys, Mater. Chem. Phys. (2017), http://dx.doi.org/10.1016/j matchemphys.2017.07.037.

[36] Y.L. Zhao, T. Yang, Y. Tong, J. Wang, J.H. Luan, Z.B. Jiao, D. Chen, Y. Yang, A. Hu, C.T. Liu, J.J. Kai, Heterogeneous precipitation behavior and stacking-fault-mediated deformation in a CoCrNi-based medium-entropy alloy, Acta Mater. 138 (2017) 72-82, http://dx.doi.org/10.1016/j.actamat.2017.07.029.

[37] S.J. Sun, Y.Z. Tian, H.R. Lin, X.G. Dong, Y.H. Wang, Z.J. Zhang, Z.F. Zhang, Enhanced strength and ductility of bulk CoCrFeMnNi high entropy alloy having fully recrystallized ultrafine-grained structure, Mater. Des. 133 (2017) 122-127, http://dx.doi.org/10.1016/j.matdes.2017.07.054.

[38] S.J. Sun, Y.Z. Tian, H.R. Lin, H.J. Yang, X.G. Dong, Y.H. Wang, Z.F. Zhang, Transition of twinning behavior in CoCrFeMnNi high entropy alloy with grain 
refinement, Mater. Sci. Eng. A 712 (2018) 603-607, http://dx.doi.org/10.1016/J. MSEA.2017.12.022.

[39] F. Otto, N.L. Hanold, E.P. George, Microstructural evolution after thermomechanical processing in an equiatomic, single-phase CoCrFeMnNi high-entropy alloy with special focus on twin boundaries, Intermetallics 54 (2014), http://dx.doi. org/10.1016/j.intermet.2014.05.014.

[40] W.H. Liu, Y. Wu, J.Y. He, T.G. Nieh, Z.P. Lu, Grain growth and the Hall-Petch relationship in a high-entropy FeCrNiCoMn alloy, Scr. Mater. 68 (2013), http://dx. doi.org/10.1016/j.scriptamat.2012.12.002.

[41] N.D. Stepanov, D.G. Shaysultanov, G.A. Salishchev, M.A. Tikhonovsky, E.E. Oleynik, A.S. Tortika, O.N. Senkov, Effect of v content on microstructure and mechanical properties of the $\mathrm{CoCrFeMnNiV}_{\mathrm{x}}$ high entropy alloys, J. Alloy. Compd. 628 (2015), http://dx.doi.org/10.1016/j.jallcom.2014.12.157.

[42] V.N. Sanin, D.M. Ikornikov, D.E. Andreev, V.I. Yukhvid, Centrifugal SHS metallurgy of nickel aluminide-based eutectic alloys, Russ. J. Non-Ferr. Met. 55 (2014) 613-619, http://dx.doi.org/10.3103/S1067821214060212.

[43] V.N. Sanin, V.I. Yukhvid, D.M. Ikornikov, D.E. Andreev, N.V. Sachkova, M.I. Alymov, SHS metallurgy of high-entropy transition metal alloys, Dokl. Phys. Chem. 470 (2016) 145-149, http://dx.doi.org/10.1134/S001250161610002X.

[44] M. Klimova, N. Stepanov, D. Shaysultanov, R. Chernichenko, N. Yurchenko, V. Sanin, S. Zherebtsov, Microstructure and mechanical properties evolution of the $\mathrm{Al}$, C-containing CoCrFeNiMn-type high-entropy alloy during cold rolling, Materials (Basel) 11 (2017) 53, http://dx.doi.org/10.3390/ma11010053.

[45] N. Kashaev, V. Ventzke, N. Stepanov, D. Shaysultanov, V. Sanin, S. Zherebtsov, Laser beam welding of a CoCrFeNiMn-type high entropy alloy produced by selfpropagating high-temperature synthesis, Intermetallics 96 (2018) 63-71, http://dx. doi.org/10.1016/j.intermet.2018.02.014.

[46] V. Sanin, D. Andreev, D. Ikornikov, V. Yukhvid, Cast intermetallic alloys and composites based on them by combined centrifugal casting-SHS process, Open J. Met. 3 (2013) 12-24, http://dx.doi.org/10.4236/ojmetal.2013.32A2003.

[47] N. Stepanov, M. Tikhonovsky, N. Yurchenko, D. Zyabkin, M. Klimova, S. Zherebtsov, A. Efimov, G. Salishchev, Effect of cryo-deformation on structure and properties of CoCrFeNiMn high-entropy alloy, Intermetallics 59 (2015) 8-17, http://dx.doi.org/10.1016/j.intermet.2014.12.004.

[48] S. Zherebtsov, N. Stepanov, Y. Ivanisenko, D. Shaysultanov, N. Yurchenko, M. Klimova, G. Salishchev, Evolution of microstructure and mechanical properties of a CoCrFeMnNi high-entropy alloy during high-pressure torsion at room and cryogenic temperatures, Metals (Basel) 8 (2018), http://dx.doi.org/10.3390/ met8020123.

[49] I.S. Wani, T. Bhattacharjee, S. Sheikh, Y.P. Lu, S. Chatterjee, P.P. Bhattacharjee, S. Guo, N. Tsuji, Ultrafine-grained $\mathrm{AlCoCrFeNi}{ }_{2.1}$ eutectic high-entropy alloy, Mater. Res. Lett. 4 (2016) 174-179, http://dx.doi.org/10.1080/21663831.2016. 1160451.
[50] I.S. Wani, T. Bhattacharjee, S. Sheikh, P.P. Bhattacharjee, S. Guo, N. Tsuji, Tailoring nanostructures and mechanical properties of $\mathrm{AlCoCrFeNi2.1}$ eutectic high entropy alloy using thermo-mechanical processing, Mater. Sci. Eng. A 675 (2016) 99-109, http://dx.doi.org/10.1016/J.MSEA.2016.08.048.

[51] I. Baker, F. Meng, M. Wu, A. Brandenberg, Recrystallization of a novel two-phase FeNiMnAlCr high entropy alloy, J. Alloy. Compd. 656 (2016) 458-464, http://dx. doi.org/10.1016/J.JALLCOM.2015.09.264.

[52] E. Nes, N. Ryum, O. Hunderi, On the Zener drag, Acta Metall. 33 (1985) 11-22, http://dx.doi.org/10.1016/0001-6160(85)90214-7.

[53] P.P. Bhattacharjee, G.D. Sathiaraj, M. Zaid, J.R. Gatti, C. Lee, C.W. Tsai, J.W. Yeh, Microstructure and texture evolution during annealing of equiatomic CoCrFeMnNi high-entropy alloy, J. Alloy. Compd. 587 (2014), http://dx.doi.org/10.1016/j. jallcom.2013.10.237.

[54] J. Zhang, D. Raabe, C.C. Tasan, Designing duplex, ultrafine-grained Fe-Mn-Al-C steels by tuning phase transformation and recrystallization kinetics, Acta Mater. 141 (2017) 374-387, http://dx.doi.org/10.1016/J.ACTAMAT.2017.09.026.

[55] M. Feuerbacher, Dislocations and deformation microstructure in a B2-ordered Al28Co20Cr11Fe15Ni26 high-entropy alloy, Sci. Rep. 6 (2016) 29700, http://dx. doi.org/10.1038/srep29700.

[56] Z. Wang, A. Genc, I. Baker, Direct versus indirect particle strengthening in a strong, ductile FeNiMnAlTi high entropy alloy, Mater. Charact. 132 (2017) 156-161, http://dx.doi.org/10.1016/J.MATCHAR.2017.08.019.

[57] S.W. Wu, G. Wang, J. Yi, Y.D. Jia, I. Hussain, Q.J. Zhai, P.K. Liaw, Strong grain-size effect on deformation twinning of an Al0.1CoCrFeNi high-entropy alloy, Mater. Res. Lett. 5 (2017) 276-283, http://dx.doi.org/10.1080/21663831.2016.1257514.

[58] S.V. Zherebtsov, G.S. Dyakonov, G.A. Salishchev, A.A. Salem, S.L. Semiatin, The influence of grain size on twinning and microstructure refinement during cold rolling of commercial-purity titanium, Metall. Mater. Trans. A 47 (2016) 5101-5113, http://dx.doi.org/10.1007/s11661-016-3679-0.

[59] N.D. Stepanov, D.G. Shaysultanov, M.A. Tikhonovsky, G.A. Salishchev, Tensile properties of the Cr-Fe-Ni-Mn non-equiatomic multicomponent alloys with different Cr contents, Mater. Des. 87 (2015) 60-65, http://dx.doi.org/10.1016/j.matdes. 2015.08.007.

[60] Y.D. Wu, Y.H. Cai, X.H. Chen, T. Wang, J.J. Si, L. Wang, Y.D. Wang, X.D. Hui, Phase composition and solid solution strengthening effect in TiZrNbMoV high-entropy alloys, Mater. Des. 83 (2015), http://dx.doi.org/10.1016/j.matdes.2015.06.072.

[61] Z. Li, F. Körmann, B. Grabowski, J. Neugebauer, D. Raabe, Ab initio assisted design of quinary dual-phase high-entropy alloys with transformation-induced plasticity, Acta Mater. 136, 2017, pp. 262-270. 〈https://www.sciencedirect.com/science/ article/pii/S1359645417305840?via\%3Dihub〉 (Accessed 31 January 2018).

[62] S.F. Liu, Y. Wu, H.T. Wang, J.Y. He, J.B. Liu, C.X. Chen, X.J. Liu, H. Wang, Z.P. Lu, Stacking fault energy of face-centered-cubic high entropy alloys, Intermetallics 93 (2018) 269-273, http://dx.doi.org/10.1016/j.intermet.2017.10.004. 